\title{
Evaluation of algal bloom mitigation and nutrient removal in floating constructed wetlands with different macrophyte species
}

Fenner, Nathalie; West, Mike; Gough, Rachel; Freeman, Christopher

\section{Ecological Engineering}

DOI:

10.1016/j.ecoleng.2017.07.033

Published: 01/11/2017

Peer reviewed version

Cyswllt i'r cyhoeddiad / Link to publication

Dyfyniad o'r fersiwn a gyhoeddwyd / Citation for published version (APA):

Fenner, N., West, M., Gough, R., \& Freeman, C. (2017). Evaluation of algal bloom mitigation and nutrient removal in floating constructed wetlands with different macrophyte species. Ecological Engineering, 108(Part B), 581-588. https://doi.org/10.1016/j.ecoleng.2017.07.033

\footnotetext{
Hawliau Cyffredinol / General rights

Copyright and moral rights for the publications made accessible in the public portal are retained by the authors and/or other copyright owners and it is a condition of accessing publications that users recognise and abide by the legal requirements associated with these rights. study or research.

- Users may download and print one copy of any publication from the public portal for the purpose of private

- You may not further distribute the material or use it for any profit-making activity or commercial gain

- You may freely distribute the URL identifying the publication in the public portal?
}

Take down policy

If you believe that this document breaches copyright please contact us providing details, and we will remove access to the work immediately and investigate your claim. 
1 Evaluation of algal bloom mitigation and nutrient removal in floating constructed

2 wetlands with different macrophyte species

3

$4 \quad$ Mike West $^{1}$, Nathalie Fenner ${ }^{1 *}$, Rachel Gough ${ }^{1}$, Christopher Freeman ${ }^{1}$

$5 \quad{ }^{1}$ School of Biological Sciences, Bangor University, Deiniol Road, Bangor, Gwynedd, LL57

$62 U W, U K$

$7 \quad *$ Corresponding author: n.fenner@bangor.ac.uk

\section{$8 \quad \underline{\text { Abstract }}$}

9 Algal blooms resulting from the eutrophication of surface waters represent a significant 10 ecological and water treatment issue. The potential for wetland systems to act as sinks for 11 various types of pollutants indicates their potential for mitigating algal blooms. Although nutrient uptake in terrestrial treatment wetland systems has received substantial attention in the literature, relatively little is known about the mechanisms involved in floating constructed wetland (FCW) function for algal control and whether plant species can optimise performance. Here, the effect of FCWs on water quality including nutrient levels and algal biomass was investigated, along with the effect of planting with different species of macrophyte. All the planted FCWs showed significant potential for algal bloom mitigation in both hypereutrophic and mesotrophic systems; algal biomass control is proposed to be due to the direct uptake of nitrate and phosphate via macrophyte roots, rather than algaecidal effect of phenolic compounds. Dissolved organic carbon (DOC) release was found to differ between species, with implications for drinking water treatment. 
In both freshwater and marine systems, the leaching of nutrients from the surrounding terrestrial environment can lead to high nutrient loading (McDowell \& Wilcock 2008). This can result in eutrophication, a process known to have deleterious effects on ecosystem goods and services. Pollutants containing nitrogen and phosphorus can drive increases in primary production. In aquatic systems this often results in the formation of algal blooms, whilst in wetland habitats, species composition shifts can be observed with increasing trophic level. Many studies on lakes and rivers have found a direct correlation between nutrient levels and algal biomass (Smith et al. 1999).

Several factors influence the degree of eutrophication including flow rate, retention time and degree of water inundation. Reviews on pollutant concentrations required in order for eutrophic conditions to arise in lentic (standing) and lotic (flowing) systems are discussed by Nürnberg (1996) and Dodds et al. (1998), respectively. Evidence presented in Dodds et al. (1998) indicates clearly that lotic, fast moving water bodies require extremely concentrated nitrogen and phosphorus inputs in order for eutrophic conditions to prevail. The slow movement of water in lakes, ponds and wetland sites make them more susceptible to the effects of enrichment due to higher water retention times.

Wetlands are biologically, geologically and chemically unique ecosystems (Kadlec \& Wallace 2008). These systems are regarded as hydrological buffers, stabilizing flow rates and ameliorating flooding and drought by recharging aquifers (Mitsch \& Gosselink 2000). The ability of natural wetlands to act as sinks for chemicals has encouraged researchers to investigate the possibility of using constructed wetlands $(\mathrm{CW})$ to treat wastewater and water of high nutrient or pollutant content, with increasingly diverse applications being seen.

The use of floating constructed wetlands (FCW), where buoyancy is engineered within the design, is a possible solution to the problem of eutrophic water bodies. These systems allow the roots of the macrophytes to be suspended in the water column, resulting in direct uptake of nutrients and therefore greater uptake rates than in benthic sediments (Headley et al. 2006). The FCW can be constructed and designed in order to deal with varying amounts of pollutant loading and the ability of the floating systems to track the water table is also advantageous in circumventing issues that can reduce performance in conventional $\mathrm{CW}$, such as lowered flow rate or water volume.

The consensus is that phosphate is generally the most limiting nutrient in aquatic ecosystems and wetlands. It can be removed in CWs through various pathways including sorption, biomass storage and cycling, microbial phosphorus in flocs, longer term accretion in soils and sediments (Kadlec \& Wallace 2008). Primary removal methods, in conservation site CWs in particular, are precipitation with other compounds, dissolution resulting in sedimentation and peat accretion (Vymazal 2007). Plant-bound phosphorus will cycle in the wetland from plants to soils to microbes, some of which will be lost from the system during biomass degradation.

Nitrate is often the dominant form of nitrogen-based pollutant in waters affected by agricultural activity due to its high solubility. Complete removal of nitrate can be achieved by microbial denitrification (Shapleigh 2013). This process converts nitrate to nitrogen gas via a number of intermediate phases. Denitrification is facilitated by microbial communities through the production of reductase enzymes (Knowles 1982). However, in many cases $\mathrm{N}_{2} \mathrm{O}$ (nitrous oxide), a potent greenhouse gas, is emitted from the CW before complete transformation to $\mathrm{N}_{2}$ (Kadlec \& Wallace 2008). 
Although it has been shown that FCWs offer significant potential in the mitigation of algal blooms through nutrient uptake (e.g. Jones et al. 2017), to date, the effect of planting with different macrophyte species has not been investigated. Thus, this paper presents the results of a study designed to test the effectiveness of FCWs planted with different macrophyte species for nutrient removal and algal bloom mitigation and the potential mechanisms involved in this process.

\section{$\underline{\text { Materials and methods }}$}

Water quality, including nutrient concentrations and algal biomass, was assessed over a 10 week period in water tanks under 5 different treatment regimes. The treatments included FCW s planted with 3 different plant species, an unplanted FCW treatment and a control (no FCW present).

\section{Experimental mesocosm set-up}

Thirty $80 \mathrm{~L}$ plastic tanks were set up in a roof top research compound (Bangor University, Wales, UK). After filling with $70 \mathrm{~L}$ of tap water, the water in the tanks was vigorously mixed in order to drive off any dissolved chlorine gas added to the water during treatment and then allowed to equilibrate for 2 days.

The experiment included 2 trophic states, namely a hypereutrophic nutrient balance $(25 \mathrm{mg} / \mathrm{L}$ nitrate, $2 \mathrm{mg} / \mathrm{L}$ phosphate) and a mesotrophic nutrient balance $(2.5 \mathrm{mg} / \mathrm{L}$ nitrate, $1 \mathrm{mg} / \mathrm{L}$ phosphate). For each trophic state, 5 different treatments were applied, with 3 replicates per trophic state/treatment combination. The 5 treatments comprised a FCW planted with Phragmites australis, Juncus effusus, Iris pseudacorus, an unplanted FCW and a control system (no FCW present).

The experimental design employed the random assignment of trophic state and treatment type to different tanks with the tanks positioned in 3 rows of 10 . Although randomly assigned, in order to achieve robust experimental design, each trophic state and treatment type occurred in each of the 3 rows. Each treatment type was then randomly positioned within the row in order to reduce any potential environmental effects due to tank position.

The nutrient concentrations required to achieve the 2 trophic states were based upon analysis carried out by Wetzel (2001), Smith et al. (1999), Nürnberg (1996) and Dodds et al. (1998) on freshwater bodies. The desired nutrient levels were achieved by the addition of concentrated $\mathrm{KNO}_{3}, \mathrm{Ca}\left(\mathrm{NO}_{3}\right)_{2} \cdot 4 \mathrm{H}_{2} \mathrm{O}$ and $\mathrm{NaH}_{2} \mathrm{PO}_{4} .2 \mathrm{H}_{2} \mathrm{O}$ solutions. The nutrient solutions were added to the tanks at the start of the experiment ( $7^{\text {th }}$ June). A secondary nutrient replenishment was performed on the $1^{\text {st }}$ of August.

\section{FCW Design and Addition to Mesocosms Systems}

The FCWs were constructed using plastic coated wire $\left(30 \mathrm{~cm}\right.$ width, $15 \mathrm{~cm}$ height, $0.0706 \mathrm{~m}^{2}$ surface area) supported by an inert foam floating ring around the circumference. A rooting media mixture of equal measures of peat, coir (coconut fibre) and finely chopped heather were used to replicate organic matter used in Welch et al. (1990). Porous liners were used in order to prevent loss of the organic media into the water column.

Systems were planted with equal quantities of plants by biomass. Phragmites australis, Juncus effusus and Iris pseudacorus species were used. When planting out the new FCWs, attached material was washed from the root zone of the plants in order to avoid 
contamination. FCWs containing Juncus effusus were planted 9 months in advance of the testing period. This was done in order to achieve a pseudo-control which aimed to investigate how performance might change with established systems.

Once fully planted, each system was rinsed with $50 \mathrm{~L}$ of tap water in order to remove any residual nutrient within the organic material added to the substrate material. This allowed for more accurate quantification of plant nutrient assimilation. Once the nutrients within the tanks had been manipulated to the appropriate levels, the FCWs were placed in the relevant tanks, with the outer floating ring allowing the vegetation to sit above the water surface.

\section{Sample collection}

Sampling was carried out weekly. The water in the tanks was thoroughly mixed before a 50 $\mathrm{mL}$ sample was collected from the water column. The $\mathrm{pH}$ and conductivity were measured on raw, unfiltered samples. Dissolved oxygen was measured in situ using a dissolved oxygen probe, calibrated prior to each sample run. Pore water dissolved oxygen measurement was carried out in situ from a $10 \mathrm{~cm}$ porous tube inserted into the system rhizosphere and sealed with a cap. Unless otherwise stated, water chemistry parameters refer to water column samples rather than the pore water.

Following measurement of $\mathrm{pH}$ and conductivity using probes, water samples were filtered through GF/C $1.2 \mu \mathrm{m}$ filter paper in order to extract an algal sample. Secondary filtration of the same samples though $0.45 \mu \mathrm{m}$ membrane filters was performed in order to allow matched sampling and prevent sample degradation. Samples were stored at $4{ }^{\circ} \mathrm{C}$ until analysis.

\section{Sample analyses}

Dissolved organic carbon (DOC) concentration was measured using an Analytical Sciences Thermalox TOC/TN analyser. In order to measure DOC the samples were acidified to between $\mathrm{pH} 2$ and 3 and sparged with oxygen for 2 minutes in order to remove inorganic carbon compounds. The instrument was calibrated using potassium hydrogen phthalate standards $(0,5,10,15,20,30$ and $40 \mathrm{mg} / \mathrm{L})$. The concentration of phenolics was determined using the spectrometric method described by Box (1983) and adapted for 96-well microplates.

The concentrations of nitrate and phosphate were measured using an 850 Professional Ion Chromatograph (Metrohm, UK Ltd., Runcorn, UK) and 858 autosampler equipped with a Thermo Fisher AS14A anion column and a Metrohm C4 cation column. Multi-ion standard were used separately for anions and cations.

Algal biomass was monitored by measuring chlorophyll- $a$ concentration using the method described by Jespersen \& Christoffersen (1987) with $100 \%$ methanol as the solvent and an incubation time of 30 minutes in a $60^{\circ} \mathrm{C}$ water bath.

\section{Statistical Analyses}

Analysis of variance (ANOVA) was conducted to investigate differences in water quality parameters between treatments. Normality and homogeneity of variance in the data could not be accurately assessed due to small sample sizes. However, ANOVA is robust to violations of these assumptions. One-way ANOVA was performed at 3 different time points: the beginning of the experiment ( $7^{\text {th }}$ of June), just before the second nutrient replenishment $\left(26^{\text {th }}\right.$ of July) and the end of the experiment ( $16^{\text {th }}$ of August). Where significant results for 
ANOVA were identified, a Tukey HSD post-hoc test was performed. Statistical analyses were conducted using version 19 of the SPSS statistical package.

\section{$\underline{\text { Results and discussion }}$}

\section{Routine Hydrochemistry}

The $\mathrm{pH}$ in the hypereutrophic control system increased dramatically on 28/6/2011 (Figure 1a). This can be linked to a rapid increase in algal biomass observed at the same time (see below). An increase in $\mathrm{pH}$ for all treatments was also observed following nutrient replenishment on the 01/8/2011, although for the Phragmites and Iris treatments the increase was less dramatic. The main driver for this effect is likely to be the growth of phytoplankton, which assimilate carbon into biomass, thereby decreasing $\mathrm{CO}_{2}$ concentrations in the water column and, in turn, increasing the $\mathrm{pH}$ (Willoughby 1976; Schippers et al. 2004).

In the mesotrophic situation (Figure $1 \mathrm{~b}$ ), $\mathrm{pH}$ in the control peaked at a similar time to the hypereutrophic control suggesting a consistent mechanism. The planted FCWs show a small amount of variation in $\mathrm{pH}$ over time, but remain slightly acidic throughout the experiment. ANOVA analysis revealed no significant differences in $\mathrm{pH}$ between treatments for the mesotrophic system for the time points analysed (Table 1), suggesting similar biogeochemical controls on $\mathrm{pH}$.

A number of significant differences were, found at the beginning of the experiment for the hypereutrophic system (Table 1), although percentage differences were modest (Figure 1a). The only other significant difference in the hypereutrophic system was for the $26^{\text {th }}$ of July, between the control treatment and the Iris treatment. These differences are likely to relate to differential nutrient uptake via plants and algae thereby affecting conductivity and in turn $\mathrm{pH}$ (Figure 2a).

The most striking overall effect, however, was that the presence of FCWs (either planted or unplanted) mitigated against the increase in $\mathrm{pH}$ observed in the control treatments at both trophic levels (Figure 1a and b).
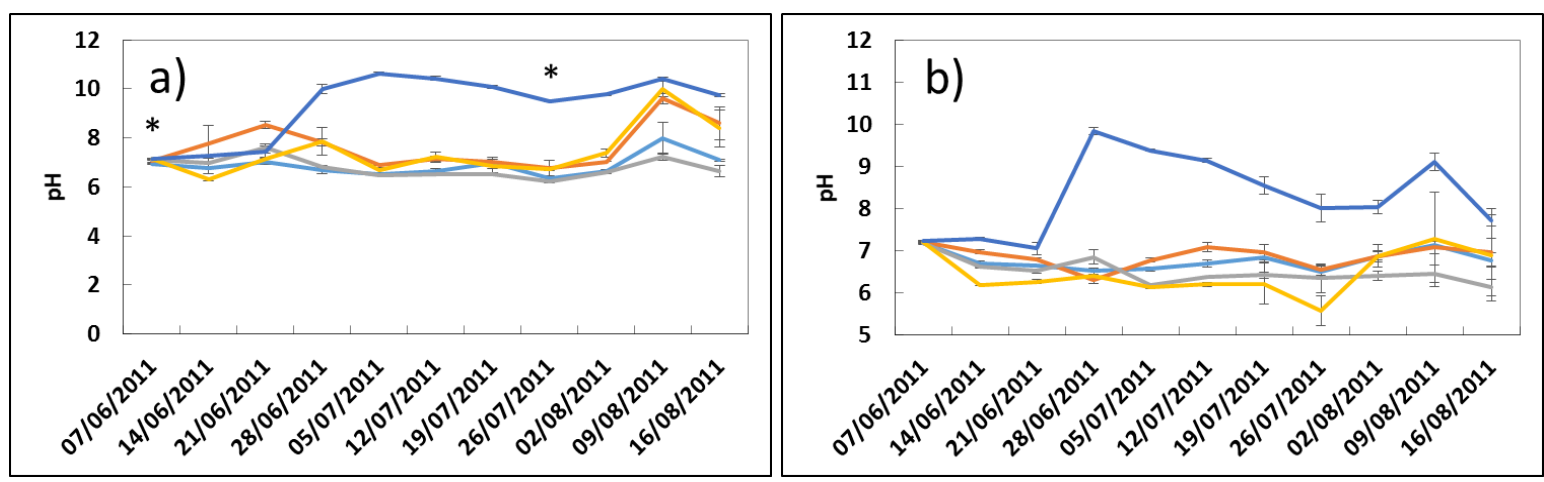

Figure 1. Water column pH for hypereutrophic (a) and mesotrophic (b) systems over 10 week experimental period showing Phragmites (light blue), Juncus (orange), Iris (grey), unplanted (yellow) and control (dark blue) treatments. Error bars represent the standard error of the mean $(n=3)$. 
Table 1. Statistically significant differences between the Phragmites (P), Juncus (J), Iris (I), unplanted $(U)$ and control $(C)$ treatments indicated by Tukey HSD post-hoc tests for Time 1

( $7^{\text {th }}$ of June), Time 2 ( $26^{\text {th }}$ of July) and Time 3 ( $16^{\text {th }}$ of August).

\begin{tabular}{|c|c|c|c|c|c|c|}
\hline & \multicolumn{2}{|c|}{$\begin{array}{l}\text { Significant differences } \\
\left.\text { Time } 1 \text { ( } 7^{\text {th }} \text { of June }\right)\end{array}$} & \multicolumn{2}{|c|}{$\begin{array}{l}\text { Significant differences } \\
\text { Time } 2\left(26^{\text {th }} \text { of July }\right)\end{array}$} & \multicolumn{2}{|c|}{$\begin{array}{l}\text { Significant differences } \\
\text { Time } 3 \text { ( } 16^{\text {th }} \text { of August) }\end{array}$} \\
\hline Parameter & $\begin{array}{c}\text { Hypereutrophi } \\
\text { c } \\
\end{array}$ & $\begin{array}{c}\text { Mesotrophi } \\
\text { c } \\
\end{array}$ & $\begin{array}{c}\text { Hypereutrophi } \\
\text { c } \\
\end{array}$ & $\begin{array}{c}\text { Mesotrophi } \\
\text { c } \\
\end{array}$ & $\begin{array}{c}\text { Hypereutrophi } \\
\text { c } \\
\end{array}$ & $\begin{array}{c}\text { Mesotrophi } \\
\text { c } \\
\end{array}$ \\
\hline $\mathrm{pH}$ & $\begin{array}{l}\text { PvJ, PvI, PvU, } \\
\text { PvC }\end{array}$ & & $\mathrm{IvC}$ & & & \\
\hline $\begin{array}{l}\text { Conductivit } \\
\text { y }\end{array}$ & & & $\begin{array}{l}\mathrm{PvJ}, \text { PvU, } \\
\text { PvC, JvI, JvC, } \\
\text { IvU, IvC, UvC }\end{array}$ & $\begin{array}{l}\text { PvJ, PvC, } \\
\text { JvI, IvU, } \\
\text { IvC, UvP, } \\
\text { UvC }\end{array}$ & $\begin{array}{l}\text { PvJ, PvC, JvI, } \\
\text { JvC, IvC, UvC }\end{array}$ & $\begin{array}{l}\text { PvC, JvI, } \\
\text { IvC, UvC }\end{array}$ \\
\hline Phenolics & $\mathrm{UvC}$ & & $\begin{array}{l}\text { PvJ, PvC, JvI, } \\
\text { IvC, UvJ, UvC }\end{array}$ & $\begin{array}{l}\text { PvJ, PvC, } \\
\text { JvI, JvU, } \\
\text { IvC, UvC }\end{array}$ & $\begin{array}{l}\text { PvJ, PvC, JvI, } \\
\text { JvU, IvC, UvC }\end{array}$ & $\begin{array}{l}\text { PvC, JvI, } \\
\text { JvU, IvC, } \\
\text { UvC }\end{array}$ \\
\hline DOC & $\mathrm{PvC}$ & & $\begin{array}{l}\text { PvJ, PvC, } \\
\text { JvU, IvJ, IvC, } \\
\text { UvC }\end{array}$ & $\mathrm{IvC}, \mathrm{UvC}$ & $\mathrm{JvU}, \mathrm{JvC}$ & $\mathrm{UvC}$ \\
\hline $\begin{array}{l}\text { Chlorophyll } \\
-\mathrm{a}\end{array}$ & & & $\mathrm{JvU}, \mathrm{JvC}$ & $\begin{array}{l}\text { PvF, JvU, } \\
\text { IvU, UvJ, } \\
\text { UvC }\end{array}$ & PvF, JvU, IvU & $\begin{array}{l}\text { PvU, JvU, } \\
\text { IvU, UvC }\end{array}$ \\
\hline Phosphate & $\begin{array}{l}\text { PvU, PvC, } \\
\text { JvU, JvC, IvU, } \\
\text { IvC }\end{array}$ & & & & $\begin{array}{l}\text { PvC, JvC, } \\
\text { IvC, UvC }\end{array}$ & \\
\hline Nitrate & & & $\mathrm{JvC}, \mathrm{UvC}$ & & & PvI, PvU \\
\hline
\end{tabular}

In the hypereutrophic treatments, conductivity (assumed to be a measure of total dissolved nutrients) showed a general decrease over time, except in the control, where conductivity generally increased (Figure 2a), probably due greater accumulation rates of nutrients compared with algal uptake and other losses from the water column. An increase in conductivity was observed in all treatments following nutrient replenishment on the $1^{\text {st }}$ of August, as might be expected.

Although conductivity values were generally lower (by $30-40 \mu \mathrm{s} / \mathrm{cm}$ ) in the mesotrophic treatments, a similar pattern of decreasing conductivity over time was observed (Figure 2b), again suggesting similar control mechanisms. Indeed, in both hypereutrophic and mesotrophic systems, a divergence in mean conductivity levels was evident as the experiment proceeded, which was confirmed by the large number of significant differences observed between treatments on the $26^{\text {th }}$ of July and at the end of the experiment (Table 1). In both systems the following order of conductivity was observed by the end of the experiment: control $>$ Juncus $>$ unplanted $>$ Phragmites $>$ Iris. Decreasing conductivity in both systems is likely to be caused by nutrients being removed and bound in the FCW both biologically and physico-chemically. However, plant species is clearly important since, Iris and Phragmites reduced the ions in the water column to the greatest degree, possibly due to enhanced direct nutrient uptake. 

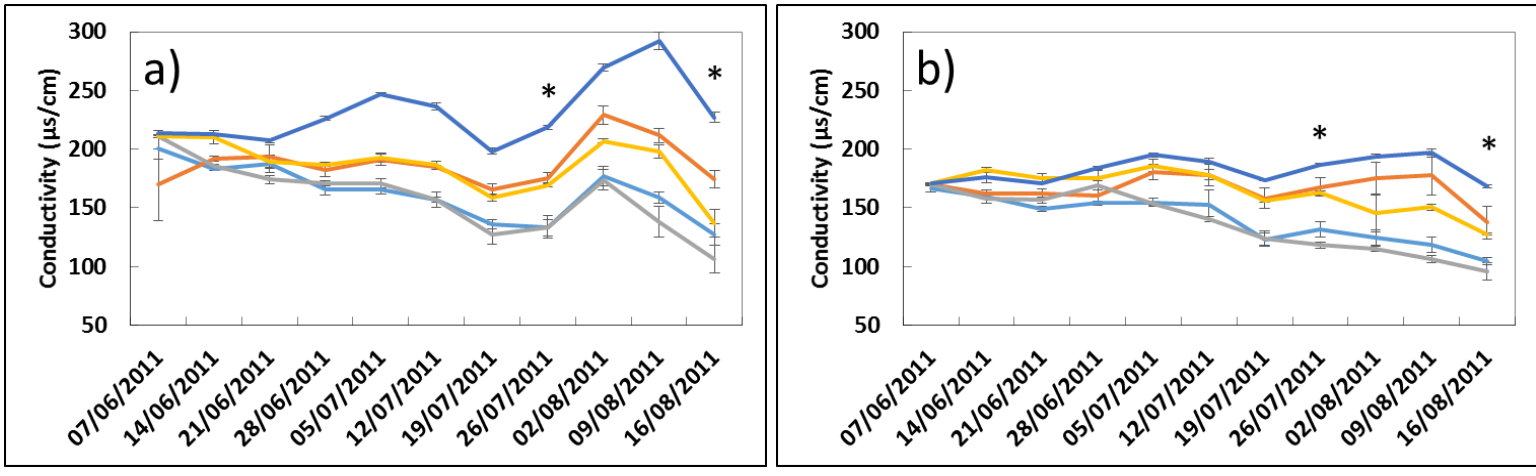

Figure 2. Water column conductivity for hypereutrophic (a) and mesotrophic (b) systems over 10 week experimental period showing Phragmites (light blue), Juncus (orange), Iris (grey), unplanted (yellow) and control (dark blue) treatments. Error bars represent the standard error of the mean $(n=3)$.

\section{Phenolics and DOC}

Overall, phenolics concentrations tended to increase during the early part of the experiment, and decrease during the latter stages (Figure $3 a$ and $b$ ). In both the hypereutrophic systems and mesotrophic systems, the highest phenolics concentrations were detected in the Iris, Phragmites and unplated systems, with intermediate concentrations observed in the Juncus, and the lowest concentrations occurring in the control treatment (Figures $3 a$ and $3 b$ ).

ANOVA analysis indicated few significant differences in phenolics levels at the beginning of the experiment (Table 1) but the difference between Juncus and control treatments versus the Iris, Phragmites and unplanted systems in the latter part of the experiment was statistically significant.
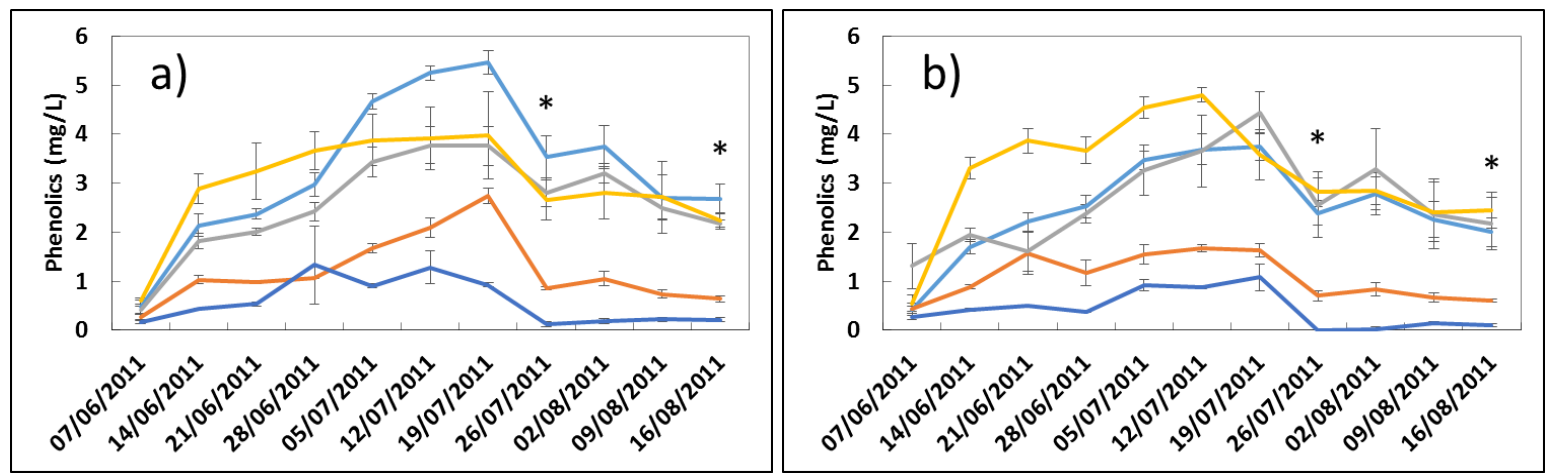

Figure 3. Water column phenolics concentration for hypereutrophic (a) and mesotrophic $(b)$ systems over 10 week experimental period showing Phragmites (light blue), Juncus (orange), Iris (grey), unplanted (yellow) and control (dark blue) treatments. Error bars represent the standard error of the mean $(n=3)$.

Given that release of phenolics from both the unplanted and planted treatments was observed, and that the control treatment (no FCW) had the lowest phenolics levels, it appears that the FCW substrate acted as a source of phenolic compounds. High phenolics levels in the unplanted treatments may also be linked with lower nutrient assimilation (due to the absence of plants) which increases algal biomass production and hence the release of algal phenolics (Willoughby 1976).

Variations in phenolics levels between planted treatments may be attributed to differences in and concentration of plant root exudates between different species. For example, Larue et al. 
(2010) describe how Iris, Typha and Phragmites exhibit varying concentrations of intracellular root tissue phenolics. This is especially evident in Iris during the spring, where intracellular phenolic concentrations are found to be more than 10 times higher than in Phragmites. However, here, in the hypereutrophic planted systems, higher water column phenolic concentrations were observed in Phragmites compared to other species suggesting this phenomenon may not be species specific but may relate to precise environmental conditions related to season, trophic level or plant microbe interactions. Indeed, under mesotrophy, Iris produced more concentrated phenolic concentrations than Phragmites.

Previous research suggests that phenolics release may contribute to algal control due to its inhibitory effect on algal growth thereby acting as a natural algaecide (Pillinger et al. 1994). However, there appeared to be no relationship between phenolics level and algal biomass (below) in this experiment. A number of reasons may explain this: a) high nutrient levels may overcome any inhibitory effect of phenolic compounds on algal growth mediated through nutrient binding (Wetzel, 2001), and b) the type of phenolic compounds, and therefore their effect, may differ depending on the plant and or algal species involved.

In both the hypereutrophic and mesotrophic treatments, Juncus treatments exhibited significantly lower phenolic concentrations than the other treatments probably due to the fact that these were pre-established; phenolic compounds along with other constituents of the DOC pool (below), leached away via rainfall and lateral water flow. This might suggest that over time, phenolics released from FCWs will decline, and thus any algaecidal properties would be lost.

In the hypereutrophic systems an increase in DOC over time was observed (Figure 4a). The control and Juncus treatments showed very similar and consistently lower concentrations of DOC throughout the experiment, supporting the suggestion that net leaching of dissolved organic carbon constituents will occur over time. Indeed, other factors that change the conditions for nutrient transformation/availability in mature compared with newly planted systems require further research (e.g. detritus and organic carbon build up, biofilm growth) and the incorporation of redox potential measurements could provide useful insight into the such processes over time.

A similar trend of increasing DOC concentration over time was observed in the mesotrophic systems (Figure $4 \mathrm{~b}$ ) but with a magnitude of approximately half the concentration observed in the hypereutrophic systems. And, DOC concentrations for individual treatments tended to diverge as the experiment progressed, as evidenced by a number of statistically significant differences on the $26^{\text {th }}$ of July and the $16^{\text {th }}$ of August (Table 1). In the hypereutrophic and mesotrophic systems, a similar order of increasing DOC concentration was observed at the end of the experiment, with the control and Juncus treatments showing the lowest levels, followed by Phragmites and Iris, and the unplanted treatment the highest concentration. The occurrence of highest levels in the unplanted treatment suggests that algal production (which was most pronounced in this treatment) contributed significantly to the DOC pool. An increase in algal biomass (below) could also explain the pulse of DOC observed in both nutrient regimes following nutrient replenishment on the $1^{\text {st }}$ of August. In the planted systems, the nutrient influx may have also increased macrophyte primary production, increasing DOC as exudate production or other associated inputs (e.g. root cell sloughing or decomposition). 

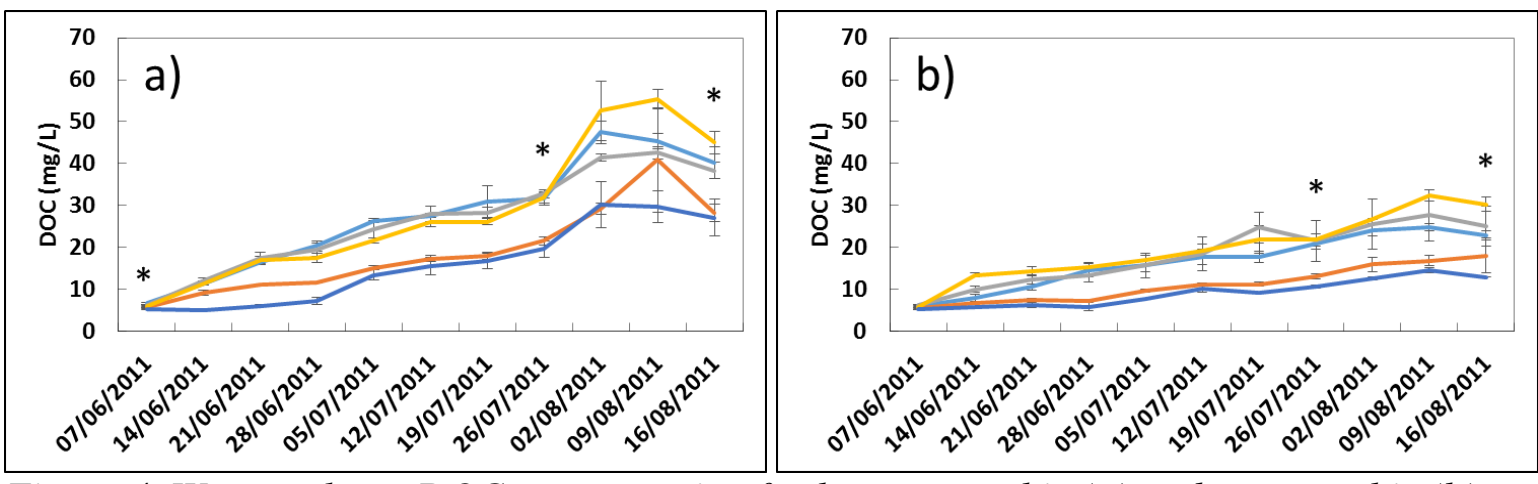

Figure 4. Water column DOC concentration for hypereutrophic (a) and mesotrophic (b) systems over 10 week experimental period showing Phragmites (light blue), Juncus (orange), Iris (grey), unplanted (yellow) and control (dark blue) treatments. Error bars represent the standard error of the mean $(n=3)$.

Kadlec \& Wallace (2008) describe the main processes occurring in a treatment wetland that contribute to the rhizosphere and pore water DOC pool. The processes included are solubilisation of chemically bound carbon and the decomposition of structurally bound carbon. Here there is no reference to the component of the carbon pool produced or removed by the plants, however, Koretsky \& Miller (2008) report that total organic carbon is typically higher in un-vegetated sites. Jones et al. (2017) also reported a release of DOC from FCWs, which they attributed to leaching from root exudates and soil organic matter. Smith \& Kalin (2000) report that DOC is released from the rhizosphere of FCWs in significant, and biologically useful quantities. And, DOC and particularly particulate organic matter released from such systems could be enough to act as a source of carbon for important remediation processes such as biomineralisation of metal pollutants and denitrification (see later). However, high DOC levels can also represent a problem for drinking water, with DOC removal representing one of the most costly aspects of drinking water treatment.

\section{Algal biomass}

In the hypereutrophic systems, both the unplanted treatment and control showed peaks of chlorophyll- $a$ above $200 \mu \mathrm{g} / \mathrm{L}$ (Figure 5a). The control showed a peak on the $5^{\text {th }}$ of July and on the $9^{\text {th }}$ of August following nutrient replenishment. Following both of these peaks senescence of algae was observed, manifested in the decrease in chlorophyll- $a$ concentration. The unplanted treatment, however, shows only one large increase in chlorophyll- $a$ concentration following the second nutrient addition, reaching a maximum of approximately $700 \mu \mathrm{g} / \mathrm{L}$. All the planted treatments showed low concentrations of chlorophyll- $a$ for the duration of the experiment, never increasing above $45 \mu \mathrm{g} / \mathrm{L}$. In the mesotrophic systems a distinct rise in chlorophyll- $a$ concentration for the unplanted treatment was also observed on the $26^{\text {th }}$ of July following nutrient replenishment, whilst relatively low concentrations were observed in the planted systems throughout the test (Figure $5 \mathrm{~b}$ ).

In both trophic regimes chlorophyll- $a$ concentration in the planted treatments was consistently lower than that observed in the unplanted or control treatments. In a number of cases these differences were found to be statistically significant (Table 1). Similarly, Jones et al. (2017) also reported significantly lower chlorophyll- $a$ levels after 4 weeks in FCW systems planted with Phragmites, compared with a control treatment. The presence of plants therefore contributes to algal bloom control. In the mesotrophic systems, lower concentrations of chlorophyll- $a$ suggest that the growth of algae was limited by nutrient availability. 
Here chlorophyll- $a$ is used to provide an estimate of total algal biomass, representing natural community compositions, however, species identity was not studied here and further research into the effects of plant species interactions with this component could prove useful in optimising FCW performance. Along with monitoring temperature and light levels, since these factors strongly influence algal growth and nutrient uptake. Similarly, investigations using a specific strain of algae would remove confounding effects of differential algal species performance, so that results can be compared.
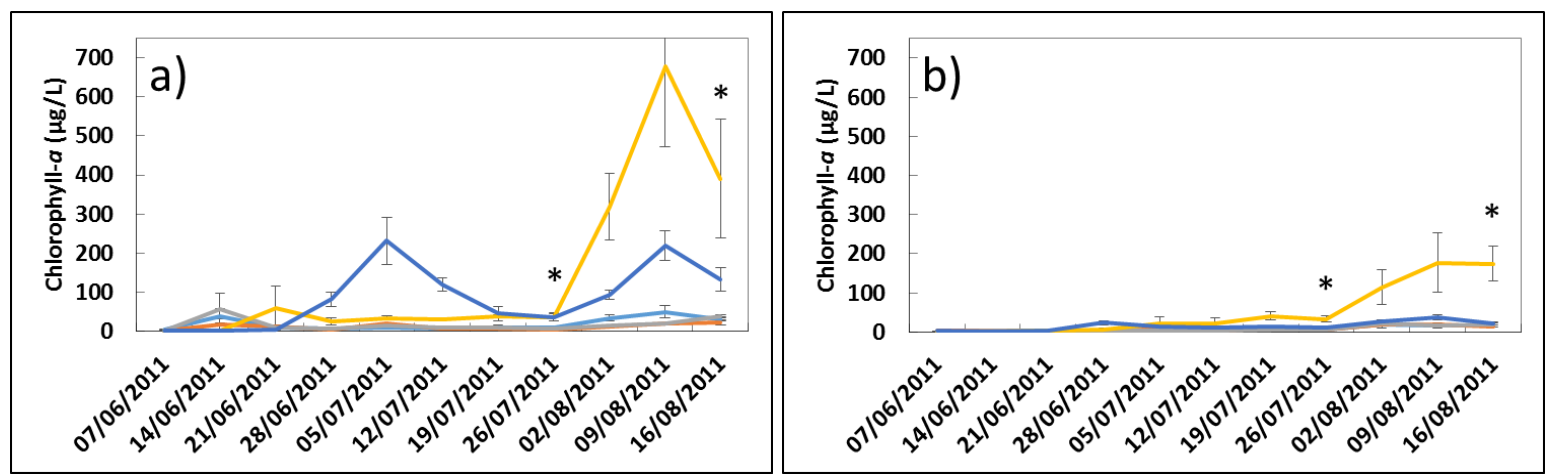

Figure 5. Water column chlorophyll-a concentration for hypereutrophic (a) and mesotrophic (b) systems over 10 week experimental period showing Phragmites (light blue), Juncus (orange), Iris (grey), unplanted (yellow) and control (dark blue) treatments. Error bars represent the standard error of the mean $(n=3)$.

\section{Nutrient cycling}

For the hypereutrophic systems, all the planted treatments showed a rapid reduction in phosphate concentration from high concentrations to virtually zero within two weeks of the start of the experiment (Figure 6a). The control and unplanted treatments both showed a slower rate of decrease, with concentrations fluctuating around $0.3 \mathrm{mg} / \mathrm{L}$ for most of the remainder of the experiment. Statistical analysis conducted at the beginning of the experiment showed a number of significant differences between treatments, although the differences were small (Table 1). At the end of the experiment, the control (no FCW) treatment showed a significantly higher phosphate level than all the other treatments.
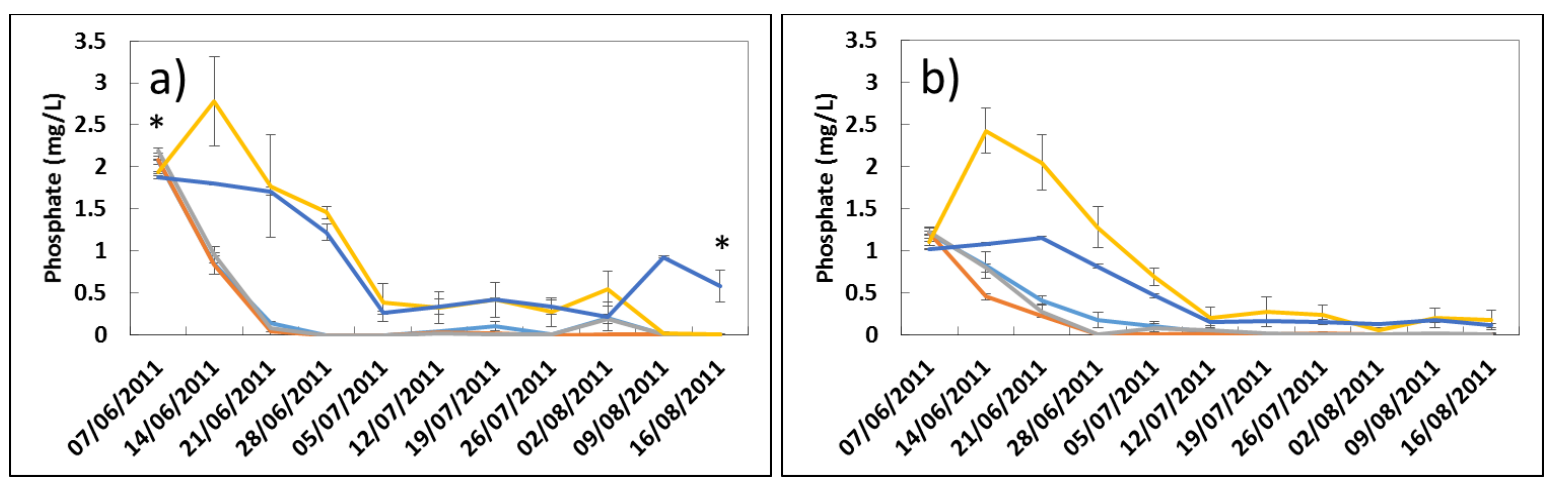

Figure 6. Water column phosphate concentration for hypereutrophic (a) and mesotrophic $(b)$ systems over 10 week experimental period showing Phragmites (light blue), Juncus (orange),

Iris (grey), unplanted (yellow) and control (dark blue) treatments. Error bars represent the standard error of the mean $(n=3)$.

For the mesotrophic systems, phosphate concentrations at the beginning of the experiment were approximately 50\% lower than in the hypereutrophic systems (Figure 6b). However, similar concentration dynamics occurred; the unplanted FCW rapidly became a source of 
phosphorus, before declining, with all treatments showing a dramatic decrease in the first few weeks of the experiment. No statistically significant differences were identified by ANOVA analysis for the time points included.

349 Phosphate is the predominant factor limiting primary production during eutrophication events early stages in the unplanted FCW system. It is likely organic material is acting as a source of phosphorus, leaching into the water column. Planted systems, in contrast, reduced the phosphate added to the systems at the start, as well as the phosphate leached by the organic material more long term.

Whilst phosphate levels in the mesotrophic treatments reached extremely low levels by the $22^{\text {nd }}$ of June, in the planted systems, the removal rate in the hypereutrophic system was more rapid. This effect can be explained by the P-k-C* equation developed by Kadlec \& Wallace (2009) for the design and scaling of CWs for water pollution control. The method requires knowledge of hydraulic efficiency within the $\mathrm{CW}$ and evenness of mixing (referred to as the Tanks in Series model) known by the parameter $\mathrm{P}$, temperature driven compound degradation rates, $\mathrm{k}$, and importantly wetland background concentration given as $\mathrm{C}^{*}$. The latter represents a system cycling and re-release parameter and a potential challenges in $\mathrm{CW}$ scaling, due to the fact that as the effluent concentration approaches $C^{*}$ value, it becomes for a pollutant to become removed or degraded. Indeed, manipulating the parameters above could allow more rigorous testing of FCW performance under varied remediation applications.

Interestingly, in the hypereutrophic system, an increase in phosphate was observed in week 10 for the control system and phosphorus release coincides with the senescence phase of the algal bloom, where chlorophyll a levels begin to decline (Figure 5a). This supports work on algal bloom senescence, post bloom formation where classic effects of eutrophication occur due to the degradation and breakdown of the algal bloom (Wetzel 2001; Schlesinger and Bernhardt 1997; Vitousek et al. 1997; Smith et al. 1999). Zhu et al. (2013) analysed the breakdown of algal blooms from Lake Taihu in the Yangtze River delta with water samples analysed for nutrient pollutant release and effect upon dissolved oxygen. During degradation, phosphate rose rapidly from zero within 15 days of sample collection with a corresponding drop in dissolved oxygen. In both the hypereutrophic and mesotrophic control system then the reduction in phosphate concentration over time is most likely due to algal uptake and subsequent bloom formation, with re-release of immobilised phosphate then occurring during decomposition processes.

In contrast, re-release of phosphate was not observed in any of the planted treatments and assuming no substantial algal bloom was formed, there would be no senescence phase during which phosphate could be re-released. Direct plant uptake is therefore likely to be the main driver of phosphate removal in these systems, above that seen due to algae in the control system (no plants or planting medium present) and due physico-chemical phosphate immobilisation along with microbial uptake in the unplanted system. 

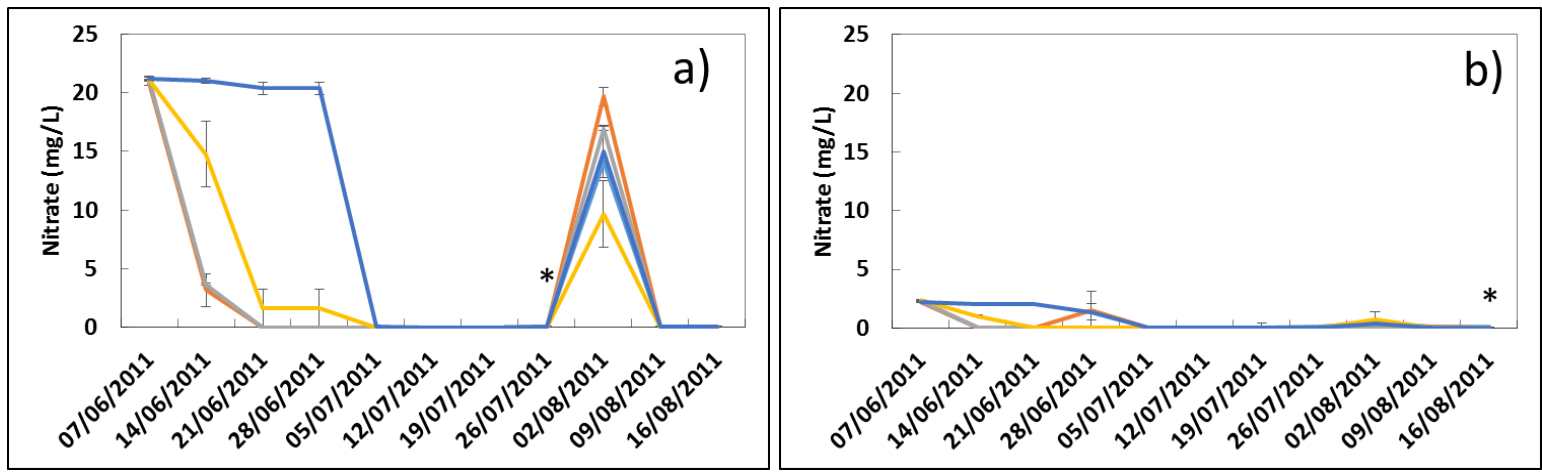

Figure 7. Water column nitrate concentration for hypereutrophic $(a)$ and mesotrophic $(b)$ systems over 10 week experimental period showing Phragmites (light blue), Juncus (orange), Iris (grey), unplanted (yellow) and control (dark blue) treatments. Error bars represent the standard error of the mean $(n=3)$.

All hypereutrophic treatments showed initial nitrate concentrations of approximately $22 \mathrm{mg} / \mathrm{L}$ (Figure 7a). For the planted treatments, this decreased to near zero after 2 weeks. The decrease in the unplanted and control treatments was delayed, particularly in the case of the control treatments which only started to decrease significantly after 3 weeks. These results indicate that the algal bloom mitigation observed in the planted treatments was the results of nutrient removal. Since a dramatic reduction in nitrate was also observed in the unplanted and control treatment, this cannot be attributed solely to plant uptake. Therefore it is likely that microbial reduction to nitrite or organic matter binding is also occurring. In the mesotrophic systems, initial nitrate concentrations were approximately one tenth of the initial concentration in the hypereutrophic systems (Figure 7b). Although statistically significant differences in nitrate concentrations were observed between treatments (Table 1), for the time points analysed, these differences were small.

Unlike the situation with phosphate where strong limitation may have allowed rapid removal of replenished phosphate, nitrate concentrations in all treatments peaked sharply following nutrient replenishment on the $1^{\text {st }}$ of August. It is notable that in all treatments and both nutrient regimes, rapid nitrate removal was observed following this increase. The fact that this coincided with substantial increases in algal biomass suggests that assimilation by algae was responsible.

Although freshwater system productivity is generally said to be limited by phosphorus inputs, nitrogen-based compounds also are known to significantly affect the potential for algal bloom formation, with nitrogen containing compounds being crucial for biomass development. Wetlands of various types are able to remediate a range of nitrogen containing pollutants. Primary mechanisms include nitrification and denitrification by microbial communities in the rhizosphere of the system (Mitsch \& Gosselink 2000). Nitrification takes place when oxygen demands for the process can be met by radial oxygen loss from arenchymous tissues in the plant root (Sorrell et al. 2000; Armstrong 1980), whereas denitrification occurs when labile carbon is plentiful and reducing conditions prevail (Vymazal 2007; Sprent 1987). Treatment wetlands are able to modify the rhizosphere environment allowing for reducing and oxidising conditions to prevail within the same "reactor" (Wiessner et al. 2006). However, it is also well known that algae also release both oxygen and labile carbon compounds, potentially promoting nitrification directly and denitrification indirectly. 


\section{Dissolved oxygen}

423 Dissolved oxygen concentrations in the water column were consistently higher in the hypereutrophic treatments compared with the mesotrophic treatments (Figure 8a) and this may relate to the relative stimulation of primary producers (plants and algae). The control showed the highest concentration of oxygen in the water column, suggesting that algal production was dominant, while the unplanted system showed the lowest levels in both trophic systems suggesting that reduction fuelled by organic matter originating in the planting media was offsetting any algal production. However, measurement of redox potential would help further elucidate these biogeochemical processes. Given the high chlorophyll a levels towards the end of the experiment (Figure 5a, b) perhaps argues against any shading effect or lower nutrient levels inhibiting algal production (Figure 6a, Figure 7a, b). No significant differences between plant species were observed in either trophic level, again suggesting similar controlling factors.
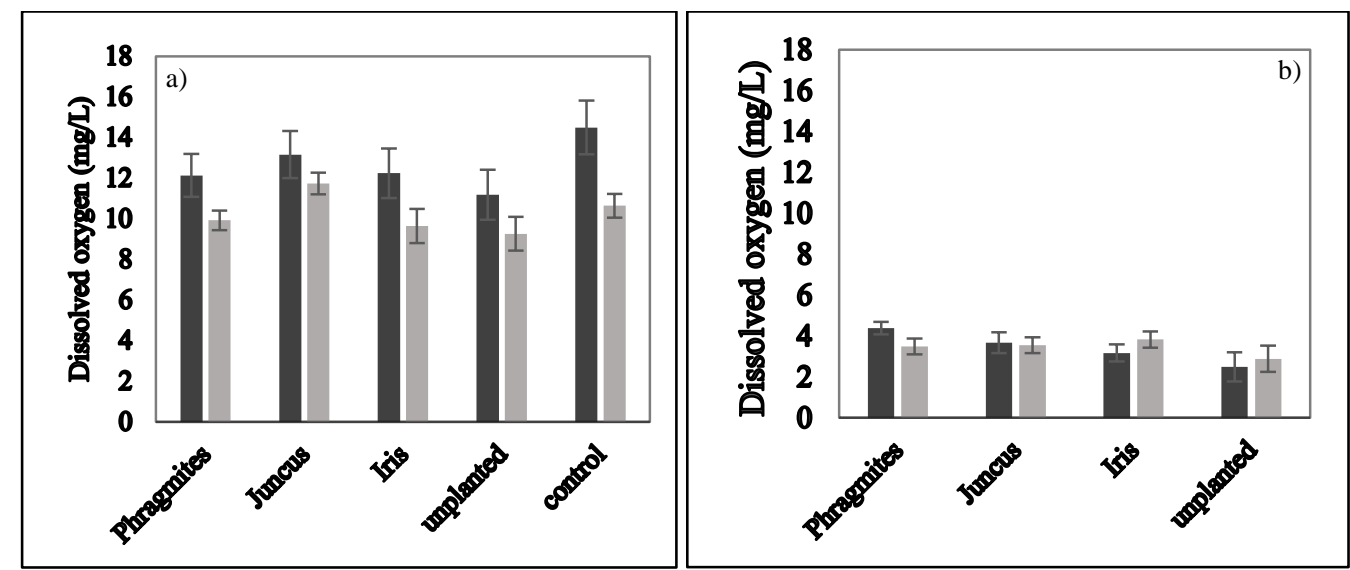

Figure 8. Summary of mean water column (a) and pore water (b) dissolved oxygen concentrations in hypereutrophic (dark grey) and mesotrophic (light grey) systems for different treatments over 10 week experimental period. Error bars represent the standard error of the mean $(n=10)$.

Within the rhizosphere of the planted FCW the oxygen concentration was at least half that in the watercolumn (Figure 8b), suggesting that algal oxygen production was dominant or that macrophyte production was offset by reduction processes in the waterlogged planting medium. However, planting (irrespective of species) increased oxygen levels compared with the unplanted system. This supports the considerable amount of literature on the adaptations of wetland macrophytes to waterlogging. Wiessner et al. (2006), for example, discuss how arenchyma tissues, which allow oxygen release into the rhizosphere, can account for up to $60 \%$ of the tissue volume in wetland macrophytes. And, vascularisation has been proven to enhance the capability of wetland plants to grow in anaerobic and waterlogged conditions (Jackson \& Armstrong 1999). Wetland plants are able to withstand varying degrees of saturations and anoxia dependant on the position along the aquatic to terrestrial continuum that they reside and the degree to which root tissues lose oxygen radially through the root surface varies with species. The latter may explain the modest variations between treatments seen here and/or differences in growth observed over the course of the testing despite initial vegetation biomass balancing.

\section{Conclusions}


Headley et al. (2006) describe multiple benefits of using FCWs over more conventional systems including the opportunity to retrofit into aquatic environments and situations where extreme fluctuations in water level are observed, but also, a significantly greater rate of plant uptake due to the direct suspension of the roots of the system. Despite significant potential for nutrient pollution remediation and algal bloom mitigation, relatively little is known about the mechanisms by which FCWs can be used to treat surface waters. Planting of FCWs with macrophytes has been shown to improve their treatment efficiency, but the effects of planting with different species has received little attention.

In both hypereutrophic and mesotrophic systems, FCWs were found to limit algal bloom formation and the associated effects on water chemistry (e.g. significantly increased $\mathrm{pH}$ ) and planted FCWs consistently performed better than the unplanted treatments. This is proposed to be due to the more rapid nutrient reduction observed in the planted treatments, with direct nutrient uptake possibly responsible, although further research on plant-microbial interactions is needed along with the role that higher dissolved oxygen levels play in the rhizosphere of planted FCW treatments. Importantly, unplanted FCWs appeared to release phosphate in the early stages of the experiment, presumably with the organic substrate acting as the source, suggesting planted systems offer more reliable phosphorus removal. Although no significant differences in algaecidal effects were observed between planted treatments, significant differences in DOC release were observed, with the Phragmites and Iris treatments showing particularly high levels. Higher DOC levels in the rhizosphere may enhance denitrification and therefore nitrate removal efficiency, but where FCW are employed in reservoir applications the drawbacks of high DOC levels in drinking water sources, including increased treatment costs and potential disinfection byproduct formation, should also be considered.

\section{Acknowledgements}

This research was part-funded by the European Social Fund (ESF) through the European Union's Convergence programme administered by the Welsh Government.

\section{$\underline{\text { References }}$}

Armstrong W. 1980. Aeration in higher plants in Woolhouse H. W (ed). Advances in botanical research, volume 7, 225-332.

Box J. D. 1983 Investigation of the Folin- Ciocalteu Phenol reagent for the determination of polyphenolic substances in natural waters. Water Research 17(5), 511-525.

Dodds W. K., Jones J. R. and Welch E. B. 1998 Suggested classification of stream trophic state: Distributions of temperate stream types by chlorophyll, total nitrogen, and phosphorus. Water Research 32(5), 1455-1462.

Headley T. R., Tanner C. C. and Council A. R. 2006 Application of floating wetlands for enhanced stormwater treatment: A review. Technical Publication no. November 2006, Auckland Regional Council.

Jackson, M.B. \& Armstrong, W., 1999. Formation of Aerenchyma and the Processes of Plant Ventilation in Relation to Soil Flooding and Submergence. Plant Biology, 1(3), pp.274-287. 
Jespersen A. M. and Christoffersen K. 1987 Measurements of chlorophyll- $a$ from phytoplankton using ethanol as extraction solvent. Archives of Hydrobiology 109(3), 445454.

Jones T. G., Willis N., Gough R. and Freeman C. 2017 An experimental use of floating treatment wetlands (FTWs) to reduce phytoplankton growth in freshwaters. Ecological Engineering 99, 316-323.

Kadlec R. H. and Wallace S. 2008 Treatment wetlands, $2^{\text {nd }}$ edn. Taylor \& Francis, New York.

Knowles R. 1982 Denitrification. Micobiology Reviews 46(1), 43-70.

Koretsky C. M. and Miller D. 2008 Seasonal influence of the needle rush Juncus roemarianus on saltmarsh pore water geochemistry. Estuaries and Coasts 31(1), 70-84.

Larue C., Korboulewsky N., Wang R. and Mévy J.P. 2010 Depollution potential of three macrophytes: exudated, wall-bound and intracellular peroxidase activities plus intracellular phenol concentrations. Bioresource Technology 101(20), 7951-7957.

McDowell R. W. and Wilcock R. J. 2008 Environmental impacts of pasture-based farming. National institute for Water and Atmospheric Research, New Zealand.

Mitsch W. J. and Gosselink J. G. 2000. Wetlands. $3^{\text {rd }}$ end. Van Nostrand Reinhold, New York.

Nürnberg G. K. 1996 Trophic state of clear and colored, soft- and hardwater lakes with special consideration of nutrients, anoxia, phytoplankton and fish. Lake and Reservoir Management 12, 432-447.

Pillinger J. M., Cooper J. A. and Ridge I. 1994 Role of phenolic compounds in the antialgal activity of barley straw. Journal of Chemical Ecology 20(7) 1557-1569.

Schippers P., Lürling M. and Scheffer M. 2004 Increase of atmospheric $\mathrm{CO}_{2}$ promotes phytoplankton productivity. Ecology Letters 7(6), 446-451.

Schlesinger W. H. and Bernhardt E.S. 1997 Biogeochemistry: an analysis of global change. $2^{\text {nd }}$ edn. Academic Press, San Diego, 139-143.

Shapleigh J. 2013 Shapleigh Labs Research undertakings. Department of Microbiology, Cornell University.

Smith M. and Kalin M. 2000 Floating wetland vegetation covers for suspended solids removal. $11^{\text {th }}$ International Conference on Wetland Systems for Water pollution Control, Quebec. Conference proceedsing 143-148.

Smith V. H., Tilman G. D. and Nekola J. C. 1999 Eutrophication: Impacts of excess nutrient inputs on freshwater, marine and terrestrial ecosystems. Environmental Pollution 100(1-3), 179-196. 
530 Sorrell B. K., Mendelssohn I. A., Mckee K. L. and Woods R. A. 2000 Ecophysiology of 531 wetland plant roots: a modelling comparison of aeration in relation to species distribution. 532 Annals of Botany 86(3), 675-685.

533 Sprent I. J. 1987. Cambridge studies in ecology; Ecology of the nitrogen cycle. CUP, UK.

534 Vitousek P. M., Mooney H. A., Lubchenco J. and Melillo J. M. 1997 Human domination of 535 Earth's ecosystems. Science 277(5325), 494-499.

536 Vymazal J. 2007 Removal of nutrients in various types of constructed wetlands. Science of 537 the Total Environment 380(1-3), 48-65.

538 Welch I. M., Barrett P. R. F., Gibson M. T. and Ridge I. 1990 Barley straw as an inhibitor of 539 algal growth I : studies in the Chesterfield Canal. Journal of Applied Phycology 2(3) 231540239.

541 Wetzel R. G. 2001. Limnology: Lake and river ecosystems. Academic Press, London, UK.

542 Wiessner A., Kuschk P., Kappelmeyer U., Bederski O., Müller R. A. and Kästner M. 2006 543 Influence of helophytes on redox reactions in their rhizosphere. Phytoremediation

544 Rhizoremediation 9A, 69-82.

545 Willoughby L. G. 1976 Freshwater biology. Hutchinson Education, UK.

546 Zhu M., Zhu G., Zhao L., Yao X., Zhang Y., Gao G. and Qin B. 2013 Influence of algal 547 bloom degradation on nutrient release at the sediment-water interface in Lake Taihu, China. 548 Environmental Science and Pollution Research 20(3), 1803-1811. 